\title{
The role of antimicrobial resistance on long-term mortality and quality of life in critically ill patients: a prospective longitudinal 2-year study
}

Triantafyllia Koukoubani ${ }^{1}$, Demosthenes Makris², Zoe Daniil² ${ }^{2}$ Theoniki Paraforou' ${ }^{1}$, Vasiliki Tsolaki², Epaminondas Zakynthinos ${ }^{2}$ and John Papanikolaou ${ }^{2 *}$ (1)

\begin{abstract}
Background: In the recent era, antimicrobial resistance has been identified as one of the most important threats to human health worldwide. The rapid emergence of antibiotic-resistant pathogens (ABRP) in the modern intensive care unit (ICU) also represents a "nightmare scenario" with unknown clinical consequences. In the Greek ICU, in particular, gram negative ABRPs are now considered endemic. However, the possible longitudinal impact of ABRPs on long-term outcomes of ICU patients has not yet been determined.
\end{abstract}

Methods: In this two-year (January 2014-December 2015) single-centre observational longitudinal study, 351 nonneurocritical ICU patients $\geq 18$ year-old were enrolled. Patients' demographic, clinical and outcome data were prospectively collected. Quality-adjusted life years (QALY) were calculated at 6, 12, 18 and 24 months after ICU admission.

Results: Fifty-eight patients developed infections due to ABRP (ABRP group), 57 due to non-ABRP (non-ABRP group), and 236 demonstrated no infection (no-infection group) while in ICU. Multiple regression analysis revealed that multiple organ dysfunction syndrome score (OR: $0.676,95 \% \mathrm{Cl} 0.584-0.782 ; \mathrm{P}<0.001)$ and continuous renal replacement therapy (OR: $4.453,95 \% \mathrm{Cl} 1.805-10.982 ; \mathrm{P}=0.001$ ) were the only independent determinants for $\mathrm{ABRP}$ infections in ICU. Intra-ICU, 90-day and 2-year mortality was $27.9 \%, 52.4 \%$ and $61.5 \%$, respectively. Compared to the non-ABRP and no-infection group, the ABRP group demonstrated increased intra-ICU, 90-day and 2-year mortality $(P \leq 0.022)$, worse 2 -year survival rates in ICU patients overall and ICU survivor subset (Log-rank test, $\mathrm{P} \leq 0.046$ ), and poorer progress over time in 2-year QALY kinetics in ICU population overall, ICU survivor and 2-year survivor subgroups $(P \leq 0.013)$. ABRP group was further divided into multi-drug and extensively-drug resistant subgroups [MDR $(n=34)$ / XDR $(n=24)$, respectively]. Compared to MDR subgroup, the XDR subgroup demonstrated increased ICU, 90-day and 2-year mortality $(P \leq 0.031)$, but similar 90-day and 2-year QALYs $(P \geq 0.549)$. ABRP infections overall $(H R=1.778,95 \% \mathrm{Cl} 1.166-2.711$; $\mathrm{P}=0.008)$, as well as $\mathrm{XDR}[\mathrm{HR}=1.889,95 \% \mathrm{Cl} 1.075-3.320 ; \mathrm{P}=0.027)$ but not MDR pathogens, were independently associated with 2-year mortality, after adjusting for several covariates of critical illness.

*Correspondence: y_papanikolaou@hotmail.com

2 Department of Critical Care, School of Medicine, University of Thessaly,

University Hospital of Larissa, Biopolis, 41110 Larissa, Greece

Full list of author information is available at the end of the article

(c) The Author(s) 2021. Open Access This article is licensed under a Creative Commons Attribution 4.0 International License, which permits use, sharing, adaptation, distribution and reproduction in any medium or format, as long as you give appropriate credit to the original author(s) and the source, provide a link to the Creative Commons licence, and indicate if changes were made. The images or other third party material in this article are included in the article's Creative Commons licence, unless indicated otherwise in a credit line to the material. If material is not included in the article's Creative Commons licence and your intended use is not permitted by statutory regulation or exceeds the permitted use, you will need to obtain permission directly from the copyright holder. To view a copy of this licence, visit http://creativecommons.org/licenses/by/4.0/. The Creative Commons Public Domain Dedication waiver (http://creativeco mmons.org/publicdomain/zero/1.0/) applies to the data made available in this article, unless otherwise stated in a credit line to the data. 
Conclusions: The present study may suggest a significant association between ABRP (especially XDR) infections in ICU and increased mortality and inability rates for a prolonged period post-discharge that requires further attention in larger-scale studies.

Keywords: Health-related quality of life, Quality-adjusted life years, Long-term outcomes, Mortality, Patient-important outcomes, Multi-drug resistance

\section{Background}

Intensive Care Unit (ICU) survivors may suffer tremendous changes in lifestyle post-discharge [1]. Critical illness may impair mental, physical and social health, limit patients' mobility and independence, and damage self-confidence, sense of hope and positive outlook [2]. These devastating consequences of critical illness, although of limited "clinical relevance", are now considered as "patient-important outcomes" (such as quality of life, functional/cognitive/neurological outcomes assessed after ICU discharge) and their role in clinical research is increasingly emphasized [3, 4]. In addition, the importance of assessing intermediate and long-term outcomes post-ICU discharge has also been encouraged [5].

Antibiotic resistant pathogens (ABRP) have been identified as one of the most important threats for the modern ICU, limiting treatment options and resulting in adverse clinical outcomes and excessive cost of care [6-8]. In the Greek ICU, in particular, Gram-negative multi-drug resistant (MDR) and extensively-drug resistant (XDR) bacteria are considered endemic $[9,10]$. The impact of antimicrobial resistance on ICU mortality has been widely studied so far [9-20]; however, the putative influence of ABRP-induced ICU infections on post-ICU patient-important, intermediate and long-term outcomes remains largely undetermined so far.

The complex consequences of critical illness are usually referred to as "quality of life" indices, on the basis of several different instruments (questionnaires, phone or personal interviews, physical examinations, chart interviews, neuro-cognitive tests) which were developed in order to assess outcomes [21]. These markers reflect the individual aspect of 'happy to live' as a result of multidimensional perceptions of physical, psychological, and social variables [2]. An established outcome index is qualityadjusted life year (QALY) index, which receives a growing interest in ICU research, as it combines both quantity and quality of life gained as a result of ICU admission and implementation of advanced therapy [1,22-26].

The aim of our study was to examine whether antimicrobial resistance in ICU is associated with increased long-term mortality and problematic quality of life for a prolonged time period post-ICU admission. For this purpose, ICU patients were divided into three subgroups: patients having suffered ABRP-induced ICU infection(s)
(ABRP-group), non-ABRP infection(s) (non-ABRPgroup) and patients who manifested no infection at all while in ICU ("no-infection" group). Survival data and QALY measurements were prospectively recorded over a two-year follow-up period.

\section{Material and methods \\ Patient population}

All consecutive adult patients admitted in the eight-bed medical-surgical ICU of a Greek regional community hospital (General Hospital of Trikala, Thessaly, Greece) between January 1, 2014, and December 31, 2015, were prospectively included. The study was approved by the Institutional Review Board and Ethics Committee of General Hospital of Trikala -ID: 123/October 15th/2013.

Written informed consent was obtained from each patient or his/her legal representative.

All patients $\geq 18$ years old were considered as eligible for the study. Post-operative patients included both elective and emergency surgical patients. Exclusion criteria were: (1) Patients confined to Hospital and/or to bed prior to ICU admission, and (2) neurosurgical patients requiring advanced neurocritical support (transmission to a tertiary center). Patients who refused to cooperate or were not found at follow-ups were also excluded from the study.

Demographic data, pre-hospitalization clinical status (QALY values estimated for the last year prior to ICU admission) and comorbidities, admitting etiology, Acute Physiology and Chronic Health Evaluation II (APACHE II) on admission, clinical data including ICU infections/ microbiology, treatment data including colistin administration, intra-ICU outcomes and survival data postdischarge were prospectively collected. The severity of multiple organ dysfunction syndrome (MODS) was assessed upon admission and during ICU infection(s), by using the MODS score as previously described [27]; the maximum MODS score value was analyzed for each patient.

Infections were defined according to criteria of Centers for Disease Control and prevention (Atlanta, GA, USA) [28]. Both ICU-acquired infections and (possible) infections upon ICU admission were evaluated for antimicrobial resistant pathogens. All admitted patients were routinely cultured on admission and sampling 
was repeated at 24- to 48-h intervals if there was suspected infection. Patients considered infected received antibiotic treatment empirically, pending the microbiology reports, for regularly 3-4 days. The negative culture results indicated discontinuation of antimicrobial chemotherapy; otherwise, the individual was considered infected.

ICU costs for each patient according to the national legislation were collected from the Economic Department of the Hospital (see also Additional file 1: Digital Content, Methods section, Clinical parameters; ICU infections; ICU costs).

\section{Evaluation of Quality-adjusted life years (QALYs)}

Quality-adjusted life years (QALYs) were calculated by using the 5-level EuroQol-5-dimensional (EQ-5D-5L) questionnaire [29-31]. The study was registered at the EuroQol Research Foundation's website (EQ-5D-5L Telephone-Paper-ID 22,972). QALY measurements were performed at 6,12, 18 and 24 months post-ICU admission by using phone interviews; proxies were also involved in the evaluation when the patient was not able to answer [for further detail see also Additional file 1: Digital Content, Methods section, Evaluation of Quality-adjusted life years (QALYs) and Additional file 2: Fig. 1].

\section{Antimicrobial-resistant pathogens}

Patients with ICU infections due to ABRP were included in the "ABRP group", patients with ICU infections due to non-ABRP were included in the "non-ABRP group" whilst the ones who manifested no infection nominated the "no-infection" group [16]. Patients who were considered infected and treated empirically, but their infection was not microbiologically-confirmed (their cultures were negative), were also classified in the "no-infection" group. In case of multiple sequential infections, especially if some were caused by ABRP and some by non-ABRP, the classifying pathogen was the most resistant organism isolated over the ICU stay; thus, patients were categorized in the "ABRP group" when at least one isolate was ABRP, otherwise they were classified in the "non-ABRP" group.

ABRPs included MDR (defined as pathogens non-susceptible to at least one agent in three or more antimicrobial categories) and XDR pathogens (defined as strains non-susceptible to at least one agent in all but two or fewer antimicrobial categories) according to previously established criteria [7]. Hence, patients with multiple sequential infections due to ABRPs were further subdivided in the "XDR subgroup" when at least one isolate was XDR, otherwise they were categorized in the "MDR subgroup".

\section{Study outcomes}

The primary goal of our study was to examine whether antimicrobial resistance in ICU is associated with (1) increased intermediate (90-day) [22] and longterm (2-year) mortality rates, and (2) impaired quality of life for a prolonged time period ( 2 years post-ICU admission).

\section{Statistical analysis}

Data is expressed as means \pm standard deviation (SD), otherwise as indicated. Kolmogorov-Smirnov test was used for normality assessment. Chi-square or Fisher's exact test were used to compare categorical variables and $t$-test or Man-Whitney $U$ test to compare continuous variables as appropriate. One-way analysis of variance (ANOVA) was used for multiple comparisons between categories. Multiple regression and multivariate linear regression analyses were used to evaluate the independent clinical determinants of antimicrobial resistance, ICU costs and 2-year QALY score, as well as to exclude co-linearity among the univariate variables included in the models. To assess differences in 2-year QALY kinetics among subgroups, mean regression lines were created and compared by using linear mixed model analysis. Kaplan Meier 2-year analysis of survival was used to assess the association of ABRP, MDR/XDR pathogens and colistin administration with patients' long-term survival. Survival curves were compared by using Log-rank test (which performs better towards the right side of the curves), Breslow test (which focuses mainly on the left side of the curves), and Tarone-Ware test (which functions better in the middle part of the curves). A Coxproportional hazard model was constructed to ascertain whether ABRP (and XDR) infections are independent predictors of outcome or rather a function of prolonged/ intensive organ support. The statistical package SPSS 17.0 (SPSS Inc., Chicago, IL, USA) was used.

\section{Results}

A total of 373 ICU patients were assessed for eligibility to participate in the study during the study period (January 1, 2014 to December 31, 2015). Twenty-two (22) of them were excluded for several reasons (eight patients did not provide written informed consent; fourteen patients refused to participate or were not found at follow-ups, so data regarding their longitudinal course post-discharge were considered as missing); thus, 351 patients were finally enrolled and analyzed.

Fifty-eight patients (16.52\%) demonstrated infection(s) due to at least one ( $\geq 1$ ) ABRP (ABRP group), 57 (16.24\%) manifested infection(s) due to $\geq 1$ non-ABRP (non-ABRP group), while $236(67.24 \%)$ manifested no infection at 
all ("no-infection" group). Eleven patients of the ABRP group $(11 / 58 ; 18.9 \%)$ demonstrated microbiological results of both ABRP and non-ABRP [11]. Patients' microbiology in our ICU population is demonstrated in detail in Table 1.

Baseline characteristics and epidemiological background of our 351 patients divided into three subgroups according to having suffered intra-ICU infections (either associated with ABRP or with non-ABRP) or not are presented in Table 2. ICU infections due to ABRP were associated significantly with more severe initial clinical condition (increased APACHE II score upon admission) but not worse preadmission status (as the latter assessed by QALY values calculated for the previous year before admission), cardiac arrest as admission etiology, as well as acute respiratory distress syndrome (ARDS), continuous renal replacement therapy (CRRT) and MODS score; among them, only MODS score (OR: 0.676, 95\%CI 0.584-0.782; $\mathrm{P}<0.001$ ) and CRRT (OR: 4.453, 95\%CI 1.805-10.982; $\mathrm{P}=0.001$ ) manifested independent association with the occurrence of ABRP infections in ICU (Additional file 1: Table 1). The duration of pre-infection ventilation was $11.76 \pm 10.2$ days in our ABRP group; sixteen out of our 19 tracheostomized patients (84.2\%) developed ABRP infection before tracheostomy was performed.

Intra-ICU and post-discharge outcome data in our study population overall $(\mathrm{N}=351)$ as well as in the subset of ICU survivors $(\mathrm{N}=253)$, divided into the three aforementioned subgroups, is presented in Table 3. ABRP infections were associated with adverse intra-ICU outcomes, including critical care myopathy and tracheostomy on discharge, prolonged mechanical ventilation and ICU stay, increased ICU costs and intra-ICU mortality (Table 3). Blood stream ABRP infections were found to constitute independent determinants of ICU cost of care (see also Additional file 1: Digital Content, Results section, as well as Additional file 1: Table 2).

The ABRP group was further divided into MDR subgroup $(\mathrm{N}=34)$ and XDR subgroup $(\mathrm{N}=24 ; 8$ of them manifested both XDR/MDR isolates). XDR subgroup was associated with more days on mechanical ventilation ( $31.9 \pm 21$ vs. $17.3 \pm 11.5, \mathrm{P}=0.001)$, prolonged ICU length of stay $(39.5 \pm 24.5$ vs. $22.6 \pm 15.1, \mathrm{P}=0.002)$, higher intra-ICU mortality $[62.5 \%(15 / 24)$ vs. $26.5 \%$ (9/34), $\mathrm{P}=0.006]$ and higher MODS score $(5.7 \pm 3.9$ vs. $3.3 \pm 3.3, \mathrm{P}=0.016$ ), yet similar APACHE II on admission (22.1 \pm 4.9 vs. $21.2 \pm 4.1, \mathrm{P}=0.431)$ compared to MDR subset.

Interestingly, patients who developed ICU infections due to XDR pathogens were of similar age $(63.3 \pm 13.8$ vs. $66.2 \pm 14.7, \mathrm{P}=0.355)$, predominantly males $[22 / 24$ (91.7\%) vs. 209/327 (63.9\%), $\mathrm{P}=0.006]$, and demonstrated higher APACHE II on admission ( $22.1 \pm 4.9$ vs. $19.2 \pm 7.2$, $\mathrm{P}=0.05)$ and MODS score $(5.7 \pm 3.9$ vs. $1.6 \pm 2.2$, $\mathrm{P}<0.001)$, compared to the rest ICU population.

\section{Association between antimicrobial resistance and long-term survival and quality of life}

In our study population, intra-ICU, 90-day and 2-year overall mortality were $27.9 \%$ (98/351), 52.4\% (184/351) and $61.5 \%$ (216/351), respectively. ABRP infections not only were associated with increased ICU mortality, but also with enhanced 90-day and 2-year mortality rates (Table 3). XDR subgroup was associated with increased 90-day and 2-year mortality compared to MDR subset (Additional file 3: Fig. 2).

Figure 1 illustrates the Kaplan-Meier 2-year survival analysis in our $351 \mathrm{ICU}$ patients overall, as well as in the subset of 253 ICU survivors, respectively, divided into the three abovementioned (ABRP, non-ABRP and "noinfection") subgroups. ABRP infections were associated with increased rates of delayed mortality in ICU patients overall (Log-rank test, $\mathrm{P}=0.046$ ) (panel A). Interestingly, when analysis was restricted only in the subset of ICU survivors, ABRP infections were markedly associated with short-term, intermediate and long-term mortality post-discharge [as assessed by Breslow $(\mathrm{P}=0.023)$ Tarone-Ware $(\mathrm{P}=0.02)$, and Log-rank $(\mathrm{P}=0.018)$ tests, respectively] (panel B). Notably (see Additional file 4: Fig. 3), the longitudinal adverse effect of antimicrobial resistance was mainly due to XDR rather than MDR pathogens, especially in the subset of ICU survivors (Log-rank, $\mathrm{P}=0.018)$. Remarkably, Cox-proportional hazard analyses demonstrate that ABRP infections overall (Table 4; Model 1), as well as XDR (Table 4; Model 2) but not MDR (Additional file 1: Table 3) infections, may represent independent predictors of long-term mortality, after adjusting for some indicators of the severity of underlying critical illness.

ICU infection(s) due to ABRP(s) were associated with worse QALY kinetics not only in our ICU population overall (Fig. 2), but also when analysis was restricted in the subset of ICU survivors (Additional file 5: Fig. 4) or even in the one of 2-year survivors (Additional file 6: Fig. 5). Interestingly, XDR and MDR subgroups demonstrated no differences in QALY values either in 90-day or in 2-year survivors (Additional file 3: Fig. 2). Multivariate regression analysis in Additional file 1: Table 4 indicates that antimicrobial resistance is not an independent determinant of long-term quality of life but rather a function of the severity of critical illness.

Patients' ABRP specific microbiology showed no association with either mortality or QALY values (Additional file 7: Fig. 6). 


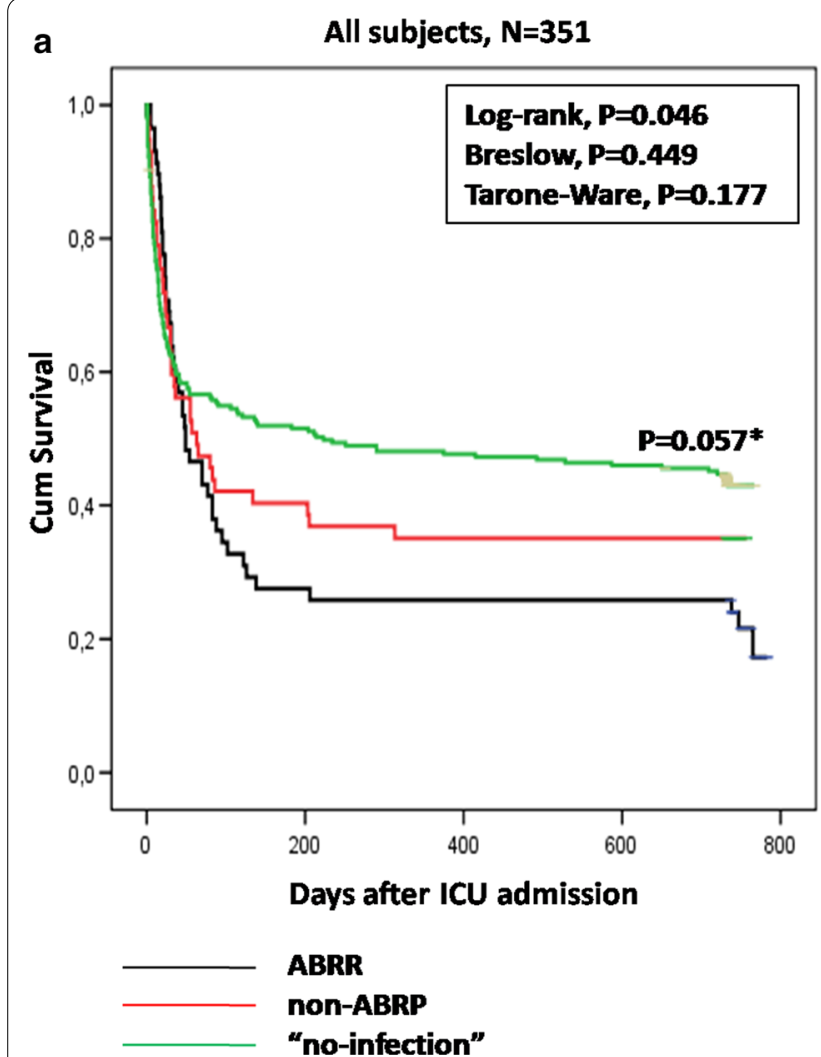

b
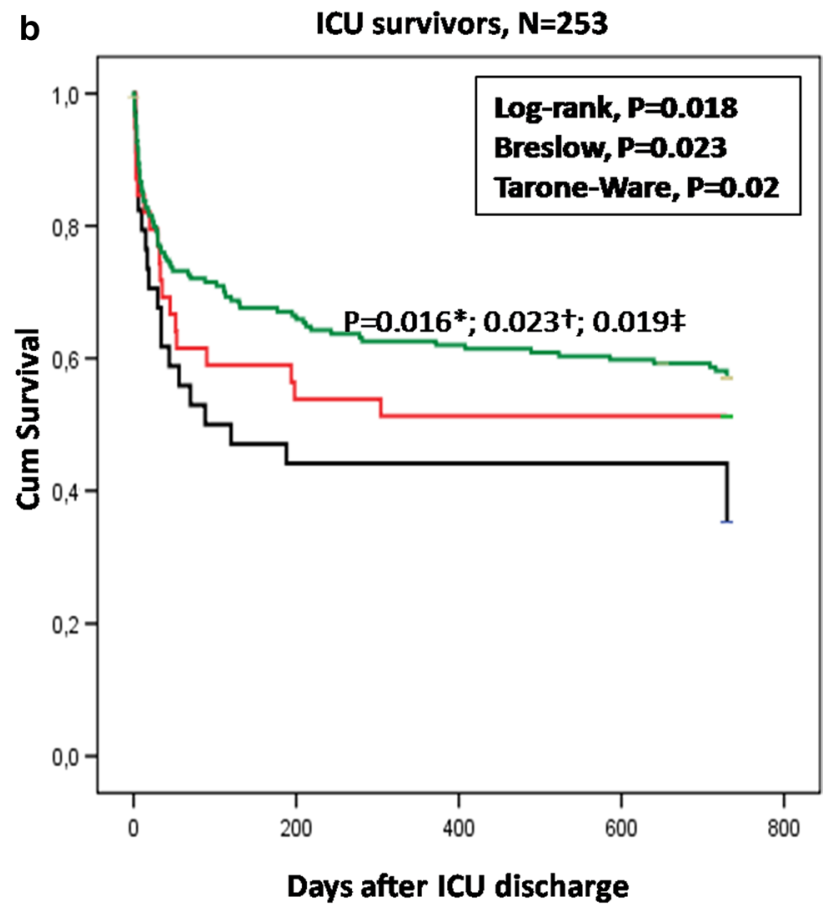

Fig. 1 Kaplan-Meier 2-year survival curves examining the effect of ABRP infections on long-term mortality in our 351 ICU patients overall (a) and in the subset of 253 ICU survivors (b). Patients were divided into three groups according to having demonstrated ABRP infections (black line), non-ABRP infections (red line) or "no-infection" at all (green line) while in ICU. Log-rank $\left(^{*}\right)$, Breslow ( $($ ) and Tarone-Ware $(\neq)$ subgroup analysis between ABRP and "no-infection" group strata. ABRP antibiotic resistant pathogen, ICU intensive care unit

Colistin administration was associated with increased longitudinal mortality rates (Additional file 8: Fig. 7) in ICU patients overall (log-rank, $\mathrm{P}=0.049$ ), but mainly in patients having survived ICU (Log-rank, $\mathrm{P}=0.018$ ). In our series, 78 patients overall required colistin treatment: $23(29.5 \%)$ due to XDR and 55 (70.5\%) due to MDR/nonABRP infections; a Kaplan-Meier 2-year survival analysis between the two subgroups (Additional file 9: Fig. 8) showed that XDR pathogens are likely to be associated with worse outcomes compared to other (MDR/nonABRP) pathogens also requiring colistin administration (Log-rank, $\mathrm{P}=0.021$ ). Colistin was also found to influence independently ICU cost of care (see also Additional file 1: Digital Content, Results section, ICU cost of care, as well as Additional file 1: Table 2).

\section{Discussion}

The most important finding of this study is that ICU infections due to antimicrobial resistant pathogens may exert a prolonged adverse impact on critically ill patients' longevity and well-being post-ICU discharge. This information is important, since it may indicate that despite the implementation of intensive care treatment, patients who develop infections due to ABRPs while in ICU are expected to have limited benefits in patient-important quality-of-life outcomes and long-term survival. Interestingly, our findings may also suggest that XDR infections represent an independent determinant of long-term survival rather than a mediating factor in declining health status of patients with more severe critical illness; however, this remains to be elucidated in larger-scale future studies.

The present study provides evidence that antimicrobial resistance in ICU is associated with adverse intra-ICU outcomes, including prolonged mechanical ventilation and ICU length of stay, and increased ICU costs [32]; in addition, our results may suggest that ABRP infections possibly impact negatively ICU mortality (Table 3 ). These data is in line with previous reports [10-14], while no significant impact on ICU mortality was found in other studies [9, 15-19]. Remarkably, a number of these studies were Greek as well $[9,10,14,18,19]$, and mainly included gram-negative ABRPs [9-19]. However, there is still limited data in the literature regarding the relationship 
Table 1 Sites of ICU infections and pathogens isolated in the subsets of our study population which have demonstrated ICU infections due to either ABRP $(N=58)$ or non-ABRP $(\mathbf{N}=\mathbf{5 7})$

\begin{tabular}{|c|c|c|c|c|c|}
\hline \multirow[t]{2}{*}{ Pathogen } & \multicolumn{5}{|c|}{ ICU infections } \\
\hline & BSI & CRBSI & Respiratory & UTI & SSI \\
\hline \multicolumn{6}{|l|}{$A B R P$ group $(N=58)$} \\
\hline In total & 57 & 12 & 2 & 2 & 2 \\
\hline Acinetobacter baumannii & 16 & 7 & 1 & - & 2 \\
\hline Klebsiella pneumonia & 32 & 5 & - & 2 & - \\
\hline Pseudomonas aeruginosa & 6 & - & 1 & - & - \\
\hline Enterobacter cloacae & 1 & - & - & - & - \\
\hline Staphylococcus aureus & 2 & - & - & - & - \\
\hline \multicolumn{6}{|l|}{ Non-ABRP group $(N=57)$} \\
\hline In total & 59 & 17 & 8 & 2 & - \\
\hline Acinetobacter baumannii & 18 & 3 & 3 & - & - \\
\hline Klebsiella pneumonia & 9 & - & 4 & 1 & - \\
\hline Pseudomonas aeruginosa & 7 & 6 & - & 1 & - \\
\hline Staphylococcus aureus & 9 & - & - & - & - \\
\hline Staphylococcus epidermidis & 10 & 6 & - & - & - \\
\hline Proteus mirabilis & 1 & - & - & - & - \\
\hline Staphylococcus saprophyticus & 2 & 2 & - & - & - \\
\hline Escherichia Coli & 2 & - & 1 & - & - \\
\hline Morganella morganii & 1 & - & - & - & - \\
\hline
\end{tabular}

ICU intensive care unit, $A B R P$ antibiotic resistant pathogen, $B S /$ blood stream infection, $C R B S I$ catheter related blood stream infection, UTI urinary tract infection, SSI surgical site infection

between ABRP infections and mortality rates post-discharge [33].

In our series, intra-ICU mortality was $27.9 \%$, and rose abruptly to $52.4 \%$ in only 90 days post-ICU admission. Beyond 90-days, long term-mortality reached a "plateau" phase, rising at a value of $61.5 \%$ at 2-year follow-up. Our results are in line with previous reports, also suggesting unacceptably high mortality rates post-ICU discharge [34]. This has been attributed to multiple reasons, such as higher pathogen virulence and/or weaker hosts [35, 36], specific type of infections (such as pneumonia or peritonitis) [37], inappropriate empirical antimicrobial therapy and/or delays in administering effective antimicrobial treatment $[19,38,39]$. Moreover, inability of the staff in lower levels of care to keep up with the needs of critically ill patients [40], absence of Intermediate Care Unit facilities [34] and premature discharge from ICU due to the constant need for beds [41] may be related to enhanced mortality rates post-discharge. However, the longitudinal impact of antimicrobial resistance on both intermediate and long term survival has not been examined so far. Our series indicates that ABRP infections in ICU (especially due to XDRs) may be associated with increased 90-day and 2-year mortality (Table 3 and Additional file 3: Fig. 2). In addition, ABRP group (mainly XDR subgroup) demonstrated worse survival curves not only in ICU patients overall, but also in the subset of ICU survivors; in the latter, it is of note that antimicrobial (possibly XDR) resistance was associated with increased short-term, intermediate as well as long-term mortality post-discharge (Fig. 1 and Additional file 4: Fig. 3). Accordingly, one could argue that ICU survivors with a history remarkable for antimicrobial resistance while in ICU may continuously be at high risk for restricted life expectancy post-discharge; however, this hypothesis, as well as the possible mechanisms mediating this relationship, warrant further investigation in future studies.

In the recent years, patient-important outcomes are gaining wide acceptance in most fields of clinical research. Apart from decreasing mortality, clinical decision-making also aims at improving quality of life and functional status in ICU survivors [4, 23]. Up to the present, several aspects of critical illness have been investigated as possible determinants of long term outcomes (including QALY assessment) post-ICU discharge, such as the duration of mechanical ventilation/ICU stay [42, 43], septic shock [44, 45], ARDS [46], COPD [47], cardiac arrest on admission [48] etc. To the best of our knowledge, the possible role of antimicrobial resistance on quality-of-life, physical and psychological well-being for a prolonged period post-ICU discharge is examined for the first time in the present investigation. Interestingly, our study may suggest that antimicrobial resistance is likely to be associated with significant impairment in health-related quality-of-life for months, even years after ICU admission. Remarkably, ABRP infections in our series were associated with reduced 6-month to 2-year QALY kinetics (Fig. 2, Additional files 5 and 6: Figs. 4 and 5); similarly to long-term mortality, this relationship mainly concerned patients who managed to survive ICU (Table 3, Additional file 5: Fig. 4); in this respect, our findings are important, since it is suggested that history of ABRP infections in ICU, apart from increased mortality, may also predict limited anticipated benefits in nonneurocritical (as was the case in our study) critically ill patients post-discharge.

Antimicrobial resistance was associated with several aspects of critical illness (Table 2) and prolonged mechanical ventilation/ICU stay in our series (Table 3). Certainly, ABRP infections occurred predominantly in the early phase of critical illness rather than in the late stage of ICU stay (as indicated by relatively short duration of pre-infection ventilation and higher incidence of antimicrobial resistance before tracheostomy). Undoubtedly, the more severe critical illness may have predisposed to both ABRP infections and adverse long-term outcomes [33]; on the other hand, ABRP infections may have 
Table 2 Epidemiological background and clinical characteristics of our study population regarding the prevalence of ICU infections [due to either ABRP $(\mathrm{N}=58)$ or non-ABRP $(\mathrm{N}=57)$ ] or not $(\mathrm{N}=\mathbf{2 3 6})$

\begin{tabular}{|c|c|c|c|c|}
\hline & $\begin{array}{l}\text { ABRP infections } \\
N=58\end{array}$ & $\begin{array}{l}\text { Non-ABRP infections } \\
N=57\end{array}$ & $\begin{array}{l}\text { No infections } \\
N=236\end{array}$ & P-value \\
\hline Age, years & $66 \pm 14.1$ & $66.8 \pm 13.7$ & $65.8 \pm 15.1$ & 0.906 \\
\hline Sex, male (\%) & $43(74.1)$ & $38(66.7)$ & $145(61.4)$ & 0.180 \\
\hline \multicolumn{5}{|l|}{ Epidemiological background } \\
\hline Previous year health-status, QALY & $0.78 \pm 0.13$ & $0.77 \pm 0.14$ & $0.79 \pm 0.14$ & 0.973 \\
\hline Obesity & $7(12.1)$ & $4(7)$ & $12(5)$ & 0.155 \\
\hline COPD & $10(17.2)$ & $12(21.1)$ & $50(21.2)$ & 0.815 \\
\hline Asthma & $0(0)$ & $0(0)$ & $4(1.7)$ & 1.000 \\
\hline Coronary artery disease & $13(22.4)$ & $15(26.3)$ & $41(17.4)$ & 0.265 \\
\hline Heart Failure & $15(25.9)$ & $17(29.8)$ & $65(27.5)$ & 0.892 \\
\hline Atrial Fibrillation & $8(13.8)$ & $4(7)$ & $23(9.7)$ & 0.472 \\
\hline Arterial Hypertension & $14(24.1)$ & $16(28.1)$ & $69(29.3)$ & 0.741 \\
\hline Diabetes Mellitus & $9(15.5)$ & 11(19.3) & $48(20.3)$ & 0.699 \\
\hline Chronic Renal Failure & $2(3.4)$ & 3(5.3) & $15(6.3)$ & 0.684 \\
\hline Previous stroke & $2(3.4)$ & $6(10.5)$ & $19(8)$ & 0.405 \\
\hline Alcohol abuse & $5(8.6)$ & $3(5.3)$ & $9(3.8)$ & 0.261 \\
\hline \multicolumn{5}{|l|}{ Admitting etiology } \\
\hline Medical critical illness & $37(63.8)$ & $42(73.7)$ & $166(70.3)$ & 0.493 \\
\hline Surgical critical illness & $21(36.2)$ & 15(26.3) & $70(29.7)$ & 0.493 \\
\hline Cardiac arrest & $7(12.1)$ & $8(14)$ & $13(5.5)$ & 0.038 \\
\hline \multicolumn{5}{|l|}{ Clinical characteristics } \\
\hline APACHE II on admission & $21.6 \pm 4.5$ & $20.6 \pm 6$ & $18.6 \pm 7.7$ & $0.006^{\mathrm{b}}$ \\
\hline Mechanical ventilation & $51(87.9)$ & $50(87.7)$ & $184(78)$ & 0.085 \\
\hline Central line placement & $54(93.1)$ & $53(93)$ & $208(88.1)$ & 0.364 \\
\hline ARDS & $23(39.7)$ & $14(24.6)$ & $39(16.5)$ & $<0.001$ \\
\hline MODS score ${ }^{27}$ & $4.3 \pm 3.7$ & $1.7 \pm 2$ & $1.3 \pm 2$ & $<0.001$ \\
\hline Sepsis (without shock) & $24(41.4)$ & $14(24.6)$ & - & 0.047 \\
\hline Septic shock & $21(36.2)$ & $9(15.8)$ & - & 0.013 \\
\hline CRRT & $11(19)$ & $7(12.3)$ & $14(5.9)$ & 0.006 \\
\hline Multiple trauma & $11(19)$ & $6(10.5)$ & $25(10.6)$ & 0.202 \\
\hline Hemorrhagic Shock & $3(5.2)$ & $3(5.3)$ & $15(6.4)$ & 0.918 \\
\hline Colistin administration & $52(89.7)$ & $26(45.6)$ & - & $<0.001$ \\
\hline Glucocorticoid administration & $19(32.8)$ & $12(21.1)$ & $59(25)$ & 0.333 \\
\hline
\end{tabular}

Continuous data are presented as means $\pm \mathrm{SD}$, categorical data as $\mathrm{n}(\%)$

ICU intensive care unit, $A B R P$ antibiotic resistant pathogen, $Q A L Y$ quality-adjusted life years, COPD chronic obstructive pulmonary disease, $A P A C H E$ II Acute Physiology and Chronic Health Evaluation Score II, ARDS acute respiratory distress syndrome, MODS multiple organ dysfunction syndrome, CRRT continuous renal replacement therapy

a $P<0.05, A B R P$ versus non-ABRP group

b $P<0.05, A B R P$ versus no-infection group

c $\mathrm{P}<0.05$, non-ABRP versus no-infection group (Bonferroni's post hoc analysis)

resulted in a more complicated and prolonged clinical course, which in turn may have led to severe persistent impairments and functional limitations. Interestingly, our study provides evidence that even in "sicker" ICU patients, infections due to either ABRPs or XDR pathogens may bear additional risk for increased long term (2-year) mortality (Table 4), but not affect 2-year QALY scores independently (Additional file 1: Table 4). Notably, the harmful effect of antimicrobial resistance (after adjusting for possible covariates of severe underlying illness) on long-term mortality is likely to be restricted to the XDR organisms rather than the MDR subset (Table 4, Additional file 1: Table 3, and Additional file 4: Fig. 3). Furthermore, specific therapeutic approaches aiming at treating resistant pathogens, such as colistin administration (Additional file 8: Fig. 7), may have also influenced 
Table 3 Intra-ICU and post-ICU outcome data in our study regarding the prevalence of ICU infections [due to either ABRP $(\mathrm{N}=58)$ or non-ABRP $(\mathrm{N}=57)]$ or $\operatorname{not}(\mathrm{N}=\mathbf{2 3 6})$

\begin{tabular}{|c|c|c|c|c|}
\hline Population overall $(\mathrm{N}=351)$ & $\begin{array}{l}\text { ABRP infections } \\
N=58\end{array}$ & $\begin{array}{l}\text { Non-ARP infections } \\
N=57\end{array}$ & $\begin{array}{l}\text { No infections } \\
N=236\end{array}$ & P-value \\
\hline \multicolumn{5}{|l|}{ Intra-ICU outcomes } \\
\hline Critical Illness Myopathy & $22(37.9)$ & $11(19.3)$ & $9(3.8)$ & $<0.001$ \\
\hline Tracheostomy on discharge & $19(15.5)$ & $11(19.3)$ & $8(3.4)$ & $<0.001$ \\
\hline Length of stay, days & $29.6 \pm 21.1$ & $16.6 \pm 13.6$ & $6.6 \pm 7.7$ & $<0.001^{\mathrm{a}, \mathrm{b}, \mathrm{c}}$ \\
\hline MV days & $23.3 \pm 17.6$ & $13.1 \pm 10.8$ & $4.6 \pm 6.7$ & $<0.001^{\mathrm{a}, \mathrm{b}, \mathrm{c}}$ \\
\hline ICU cost/patient, euros & $13,515 \pm 7761$ & $8330 \pm 5698$ & $4183 \pm 3877$ & $<0.001^{a, b, c}$ \\
\hline Intra-ICU mortality & $24(41.4)$ & $18(31.6)$ & $56(23.7)$ & 0.022 \\
\hline \multicolumn{5}{|l|}{ Post-ICU outcomes } \\
\hline 90-day mortality & $42(72.4)$ & $33(57.9)$ & $109(46.2)$ & 0.001 \\
\hline 2-year mortality & $46(79.3)$ & $37(64.9)$ & $133(56.36)$ & 0.005 \\
\hline 0.5-year QALYs & $0.041 \pm 0.085$ & $0.073 \pm 0.106$ & $0.057 \pm 0.097$ & 0.077 \\
\hline 1-year QALYS & $0.105 \pm 0.219$ & $0.180 \pm 0.265$ & $0.142 \pm 0.245$ & 0.098 \\
\hline 1.5-year QALYs & $0.167 \pm 0.358$ & $0.289 \pm 0.433$ & $0.228 \pm 0.4$ & 0.101 \\
\hline 2-year QALYS & $0.228 \pm 0.501$ & $0.399 \pm 0.604$ & $0.313 \pm 0.559$ & 0.101 \\
\hline ICU survivors $(N=253)$ & $N=34$ & $N=39$ & $N=180$ & \\
\hline 90-day mortality & $18(52.9)$ & $15(38.5)$ & $53(29.4)$ & 0.024 \\
\hline 2-year mortality & $22(64.7)$ & $19(48.7)$ & $103(57.2)$ & 0.061 \\
\hline 0.5-year QALYs & $0.070 \pm 0.102$ & $0.107 \pm 0.113$ & $0.159 \pm 0.142$ & $0.001^{b}$ \\
\hline 1-year QALYs & $0.179 \pm 0.263$ & $0.264 \pm 0.285$ & $0.380 \pm 0.341$ & $0.002^{b}$ \\
\hline 1.5-year QALYs & $0.285 \pm 0.432$ & $0.423 \pm 0.468$ & $0.594 \pm 0.543$ & $0.003^{b}$ \\
\hline 2-year QALYs & $0.389 \pm 0.608$ & $0.584 \pm 0.654$ & $0.808 \pm 0.747$ & $0.004^{b}$ \\
\hline
\end{tabular}

Continuous data are presented as means $\pm \mathrm{SD}$, categorical data as $\mathrm{n}(\%)$

ICU intensive care unit, $A B R P$ antibiotic resistant pathogen, $M V$ days days on mechanical ventilation, $Q A L Y$ quality-adjusted life years

a $\mathrm{P}<0.05, \mathrm{ABRP}$ versus non-ABRP group

b $P<0.05, A B R P$ versus no-infection group

c $P<0.05$, non-ABRP versus no-infection group (Bonferroni's post hoc analysis)

long-term outcomes. Of course, colistin was the main regimen used for ABRP infections, hence its possible long-term consequences possibly reflect the ones of coinciding antimicrobial resistance (especially of XDR organisms, Additional file 9: Fig. 8). Finally, post-ICU care facilities and rehabilitation centers may contain numerous niches of MDR/XDR bacteria (i.e. infected patients, biofilms, toilets, surfaces, keyboards), which in turn may constitute "virulence-like" community-resistance reservoirs for secondary infection outbreaks [8, 44]. Nevertheless, our limited data may indicate a negative effect of antimicrobial resistance in declining health status, especially in the subset of the more severe critically ill. In this respect, prevention against $A B R P$ infections might be of fundamental importance in modifying the clinical course of patients with an "a priori" dismal prognosis.

A few limitations to the study deserve mention. First, we used consecutive two-year sampling in order to have valid and meaningful results on the role of antimicrobial resistance in affecting long-term outcomes; however, we certainly admit that our findings (especially on the role of
XDRs on critically ill patients' longevity post-discharge) should be validated in larger-scale studies in the future. Second, most of our infections were non-catheter-related blood stream infections, while respiratory infections were far less common in our cohort. One could argue that the synthesis of our ICU infections and its specific microbiology (mainly gram negative bacteria) may have interfered with our findings. Certainly, genetic and geographic differences may exert diverse influence on the clinical phenotypes of special diseases in different populations. Furthermore, it has been shown [49] that some organ failures (i.e. cardiovascular system) may adversely affect outcomes of ICU patients more than others; however, the MODS score we used was inadequate to examine potential longitudinal differences among specific organ failures. Moreover, a drawback of the study is the likelihood of misclassifying a culture-negative infection as no infection at all. However, this possibility was small, by carefully culturing in concert with the routine microbiological sampling of the department. Finally, meningitis/ventriculitis due to ABRPs, which has shown 


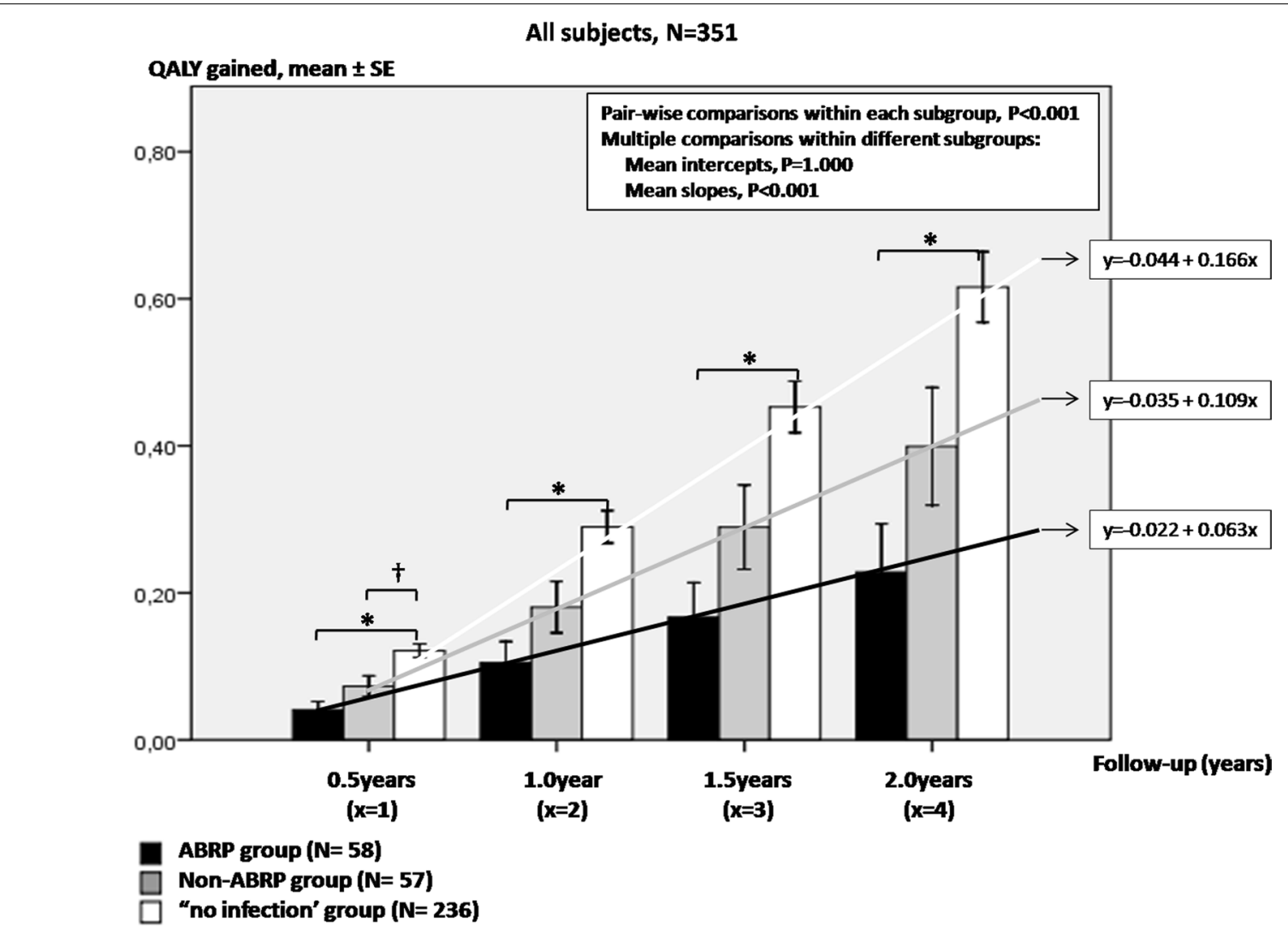

Fig. 2 Two-year QALY kinetics in ABRP, non-ABRP and "no-infection" groups in our 351 patients overall. Bars and vertical lines indicate mean QALY values and standard errors, respectively. QALY kinetics is indicated by the corresponding mean regression line for ABRP group (black line), non-ABRP group (gray line) and "no-infection" group (white line). The ABRP group displays the worse progress in QALY kinetics over time (lower slope of its corresponding mean regression line) compared to the two other groups. QALY, quality-adjusted life years; SE, standard error; ABRP, antibiotic resistant pathogen; Intercept of the regression line, the QALY value where the regression line crosses the $y$-axis at the theoretical day, 0 ; Slope of the regression line, the rate at which QALY values change between two-consequent follow-up examinations. ${ }^{*} \mathrm{P}<0.001 ;+\mathrm{P}<0.05$

Table 4 Cox regression survival analysis examining the effect of ABRP and XDR infections (Model 1 and 2, respectively) on 2-year mortality, after adjusting for possible covariates of severe underlying illness

\begin{tabular}{|c|c|c|c|c|c|c|c|c|}
\hline & \multicolumn{4}{|c|}{ Model 1} & \multicolumn{4}{|c|}{ Model 2} \\
\hline & \multirow[t]{2}{*}{ HR } & \multicolumn{2}{|l|}{$95 \% \mathrm{Cl}$} & \multirow[t]{2}{*}{$P$ value } & \multirow[t]{2}{*}{$\overline{H R}$} & \multicolumn{2}{|l|}{$95 \% \mathrm{Cl}$} & \multirow[t]{2}{*}{$P$ value } \\
\hline & & Lower & Upper & & & Lower & Upper & \\
\hline APACHE II & 1.099 & 1.075 & 1.124 & $<0.001$ & 1.100 & 1.076 & 1.125 & $<0.001$ \\
\hline MODS score ${ }^{27}$ & 1.146 & 1.083 & 1.213 & $<0.001$ & 1.140 & 1.077 & 1.207 & $<0.001$ \\
\hline ARDS & 0.786 & 0.553 & 1.115 & 0.177 & 0.797 & 0.563 & 1.128 & 0.200 \\
\hline CRRT & 1.248 & 0.776 & 2.007 & 0.360 & 1.384 & 0.866 & 2.213 & 0.174 \\
\hline MV prior to infection & 0.741 & 0.494 & 1.111 & 0.147 & 0.707 & 0.470 & 1.062 & 0.095 \\
\hline Cardiac arrest & 1.030 & 0.641 & 1.657 & 0.901 & 1.026 & 0.638 & 1.650 & 0.915 \\
\hline ABRP infections & 1.778 & 1.166 & 2.711 & 0.008 & - & - & - & - \\
\hline XDR infections & - & - & - & - & 1.889 & 1.075 & 3.320 & 0.027 \\
\hline
\end{tabular}

$A B R P$ antibiotic resistant pathogens, $X D R$ extensively-drug resistant pathogens, $C$ confidence interval, $H R$ hazard ratio, $A P A C H E$ II Acute Physiology and Chronic Health Evaluation Score II, MODS multiple organ dysfunction syndrome, ARDS acute respiratory distress syndrome, CRRT continuous renal replacement therapy, MV mechanical ventilation

Variables included in theModels were assessed for multicolinearity issues; All Variable Inflation Factors (VIF) $\leq 1.796$ 
significant diagnostic performance in post-neurosurgical patients [50], was not examined in our series.

\section{Conclusions}

The present prospective study demonstrated a significant association between ABRP (especially XDR) infections in ICU and increased mortality/inability rates for a prolonged period post-discharge. This relationship is likely to mainly concern patients with more severe critical illness, who manage to survive ICU though; in this respect, a history remarkable of antimicrobial resistance while in ICU should raise awareness for increased risk post-discharge and reconsider the anticipated benefits in long-term longevity and well-being, especially in patients with more severe critical illness and/or complex course of hospitalization.

\section{Supplementary Information}

The online version contains supplementary material available at https://doi. org/10.1186/s12955-021-01712-0.

\section{Additional file 1. Details in methodology used, results obtained.}

Additional file 2: Supplemental Figure 1 Examples of calculation of QALY-gained in our study. A. QALYs-gained by ICU treatment in a patient having survived the 2-year follow-up (QALYs gained= area $A+$ area $B$ + area $C+$ area D). B. QALYs-gained by ICU treatment in the theoretical patient who died between the 12-month and the 18-month follow-up (QALYs gained $=$ area $A+$ area $B+$ area $C$ ). $H R Q O L=$ health-related quality of life; $\mathrm{HRQOL}_{1,2,4}=$ utility index values at 6,12,18 and 24-month followup, respectively; ICU = intensive care unit; $Q A L Y S=$ quality-adjusted life years.

Additional file 3: Supplemental Figure 2. Long-term outcomes in the MDR/XDR subgroups of our 58 patients with antibiotic resistant pathogens. In the upper panel, bars represent the number of 90-day (A) and 2-year (B) survivors and non-survivors with MDR and XDR infections; percentages within grey bars represent mortality in each category. In the lower panel, bars and vertical lines indicate mean QALY values and standard errors in 90-day and 2-year survivors, respectively. MDR= multi-drug resistant pathogen; $\mathrm{XDR}=$ extensively-drug resistant pathogen; $\mathrm{QALY}=$ quality-adjusted life years.

Additional file 4: Supplemental Figure 3. Kaplan-Meier 2-year survival curves examining the effect of ABRP infections on long-term mortality post-discharge. Analysis was performed in our 351 ICU patients overall (panel A), and in the subset of 253 ICU survivors (panel B). Patients were divided into four groups according to having demonstrated MDR infection(s) (black dotted line), XDR infection(s) (continuous black line), infections due to non-ABRPs (red line) or "no-infection" at all (green line) while in ICU. $A B R P=$ antibiotic resistant pathogen; $M D R=$ multi-drug resistant; $X D R=$ extensively-drug resistant; $I C U=$ intensive care unit.

Additional file 5: Supplemental Figure 4. Two-year QALY kinetics in ABRP, non-ABRP and "no-infection" subgroups of our ICU survivors $(\mathrm{N}=253)$. Bars and vertical lines indicate mean QALY values and standard errors, respectively. ABRP group demonstrates lower increase in QALYS over time (markedly depressed slope of the corresponding mean regression line) compared to its counterparts. QALY= quality-adjusted life years; $\mathrm{ABRP}=$ antibiotic resistant pathogen; $\mathrm{ICU}=$ intensive care unit; $\mathrm{SE}=$ standard error; Intercept of the regression line $=$ the QALY value where the regression line crosses the $y$-axis at the theoretical day $=0$; Slope of the regression line $=$ the rate at which QALY values change between twoconsequent follow-up examinations. ${ }^{*} \mathrm{P}<0.001$.
Additional file 6: Supplemental Figure 5. Two-year QALY kinetics in ABRP, non-ABRP and "no-infection" subgroups of our 2-year survivors $(\mathrm{N}=135)$. Bars and vertical lines indicate mean QALY values and standard errors, respectively. ABRP group demonstrates lower increase in QALYS over time (lower slope of the corresponding mean regression line) compared to its counterparts. QALY = quality-adjusted life years; $A B R P=$ antibiotic resistant pathogen; $\mathrm{SE}=$ standard error; Intercept of the regression line $=$ the QALY value where the regression line crosses the $y$-axis at the theoretical day $=0$; Slope of the regression line $=$ the rate at which QALY values change between two-consequent follow-up examinations. ${ }^{*} P<0.05$.

Additional file 7: Supplemental Figure 6. Long-term outcomes in our 58 ABRP patients according to underlying pathogen. In the upper panel, bars represent number of 90-day (A) and 2-year (B) survivors and nonsurvivors with respect to underlying pathogen(s). In the lower panel, bars and vertical lines indicate mean QALY values and standard errors in 90-day and 2-year survivors regarding the underlying pathogen(s), respectively. $\mathrm{ABRP}=$ antibiotic resistant pathogens; $\mathrm{QALY}=$ quality-adjusted life years; $\mathrm{Ab}=$ Acinetobacter baumannii; Ent/ter=Enterobacter cloacae; $\mathrm{KPC}=$ Klebsiella pneumonia producing carbapenemases; $\mathrm{Pa}=$ Pseudomonas aeruginosa; $\mathrm{Sa}=$ staphylococcus aureus.

Additional file 8: Supplemental Figure 7. Kaplan-Meier survival curves examining the effect of colistin administration in ICU on long-term mortality post-discharge. Analysis was performed in our 351 ICU patients overall (panel A), and in the subset of $253 \mathrm{ICU}$ survivors (panel B). ICU= intensive care unit.

Additional file 9: Supplemental Figure 8. Kaplan-Meier survival curves examining the effect of XDR versus non-XDR (MDR plus non-ABRP) infections on 2-year mortality in our 78 patients treated with colistin. $\mathrm{XDR}=$ extensively-drug resistant pathogens; $\mathrm{MDR}=$ multidrug resistant pathogens; $A B R P=$ antibiotic resistant pathogens.

\section{Abbreviations}

ICU: Intensive Care Unit; ABRP: Antibiotic resistant pathogen; HR: Hazard ratio; MDR: Multi-drug resistant; XDR: Extensively-drug resistant; QALY: Qualityadjusted life year; OR: Odds ratio; Cl: Confidence interval; APACHE II: Acute Physiology and Chronic Health Evaluation II; HRQoL: Health related quality of life; EQ-5D-5L: EuroQol-5 dimensions-5 levels; SD: Standard deviation; MODS: Multiple organ dysfunction syndrome; LOS: Length of ICU stay.

\section{Acknowledgements}

Not applicable.

\section{Authors' contributions}

Study concept and design, JP, DM, ZD and EZ. Data acquisition, TK and TP. Analysis and interpretation of data, JP, VT, and EZ. Drafting of the manuscript, JP and TK. Critical revision of the article, DM, ZD, TP, VT, and EZ. All authors read and approved the final version of the manuscript submitted for publication.

\section{Funding}

This research did not receive any specific grant from funding agencies in the public, commercial, or not-for-profit sectors.

\section{Availability of data and materials}

The datasets used and/or analysed during the current study are available from the corresponding author on reasonable request.

\section{Ethics approval}

The study was approved by the Institutional Review Board and Ethics Committee of General Hospital of Trikala (ID: 123/October 15th/2013).

\section{Consent for publication}

Written informed consent was obtained for all patients participated in the study.

\section{Competing interests}

The authors declare that they have no competing interests. 


\author{
Author details \\ ${ }^{1}$ Department of Critical Care, General Hospital of Trikala, Thessaly, Greece. \\ ${ }^{2}$ Department of Critical Care, School of Medicine, University of Thessaly, \\ University Hospital of Larissa, Biopolis, 41110 Larissa, Greece.
}

Received: 6 September 2020 Accepted: 18 February 2021

Published online: 03 March 2021

\section{References}

1. Hashem MD, Nallagangula A, Nalamalapu S, Nunna K, Nausran U, Robinson KA, Dinglas VD, Needham DM, Eakin MN. Patient outcomes after critical illness: a systematic review of qualitative studies following hospital discharge. Crit Care. 2016;20(1):345. https://doi.org/10.1186/s1305 4-016-1516-X

2. Bein T, Weber-Carstens $S$, Apfelbacher $C$. Long-term outcome after the acute respiratory distress syndrome: different from general critical illness? Curr Opin Crit Care. 2018;24(1):35-40. https://doi.org/10.1097/MCC.00000 00000000476

3. Guyatt G, Montori V, Devereaux PJ, Schunemann H, Bhandari M. Patients at the center: in our practice, and in our use of language. ACP J Club. 2004;140(1):A11-2.

4. Gaudry S, Messika J, Ricard JD, Guillo S, Pasquet B, Dubief E, Boukertouta T, Dreyfuss D, Tubach F. Patient-important outcomes in randomized controlled trials in critically ill patients: a systematic review. Ann Intensive Care. 2017;7(1):28. https://doi.org/10.1186/s13613-017-0243-z.

5. Angus DC, Carlet J, 2002 Brussels Roundtable Participants. Surviving intensive care: a report from the 2002 Brussels Roundtable. Intensive Care Med. 2003;29(3):368-77. https://doi.org/10.1007/s00134-002-1624-8.

6. Ventola CL. The Antibiotic resistance crisis. Part1: causes and threats. P\&T. 2015;40:277-83.

7. Magiorakos A, Srinivasan A, Carey RB, Carmeli Y, Falagas ME, Giske CG, Harbarth S, Hindler JF, Kahlmeter G, Olsson-Liljequist B, Paterson DL, Rice LB, Stelling J, Struelens MJ, Vatopoulos A, Weber JT. Monnet DL:Multidrugresistant, extensively drug-resistant and pandrug-resistant bacteria: an international expert proposal for interim standard definitions for acquired resistance. Clin Microbiol Infect. 2012;18:268-81.

8. Miyakis S, Pefanis A, Tsakris A. The challenges of antimicrobial drug resistance in Greece. Clin Infect Dis. 2011:53:177-84. https://doi.org/10.1093/ cid/cir323.

9. Routsi C, Pratikaki M, Platsouka E, Sotiropoulou C, Nanas S, Markaki V, Vrettou C, Paniara O, Giamarellou H, Roussos C. Carbapenem-resistant versus carbapenem-susceptible Acinetobacter baumanii bacteremia in a Greek intensive care unit: risk factors, clinical features and outcomes. Infection. 2010:38:173-80. https://doi.org/10.1007/s15010-010-0008-1.

10. Michalopoulos A, Falagas ME, Karatza DC, Alexandropoulou P, Papadakis E, Gregorakos L, Chalevelakis G, Pappas G. Epidemiologic, clinical characteristics, and risk factors for adverse outcome in multiresistant gramnegative primary bacteremia of critically ill patients. Am J Infect Control. 2010;39:396-400. https://doi.org/10.1016/j.ajic.2010.06.017.

11. Combes A, Luyt CE, Fagon JY, Wolff M, Trouillet JL, Chastre J. Impact of piperacillin resistance on the outcome of Pseudomonas ventilatorassociated pneumonia. Intensive Care Med. 2006;32:1970-8. https://doi. org/10.1007/s00134-006-0355-7.

12. Parker CM, Kutsogiannis J, Muscedere J, Cook D, Dodek P, Day AG, Heyland DK, Canadian Critical Care Trials Group. Ventilator-associated pneumonia caused by multidrug-resistant organisms or Pseudomonas aeruginosa: prevalence, incidence, risk factors, and outcomes. J Crit Care. 2008;23:18-26. https://doi.org/10.1016/j.jcrc.2008.02.001.

13. Dautzenberg MJ, Wekesa AN, Gniadkowski M, Antoniadou A, Giamarellou H, Petrikkos GL, Skiada A, Brun-Buisson C, Bonten MJM, Derde LPG, Mastering hOspital Antimicrobial Resistance in Europe Work Package 3 Study Team. The association between colonization with carbapenemase-producing enterobacteriaceae and overall ICU mortality: an observational cohort study. Crit Care Med. 2015:43:1170-7. https://doi.org/10.1097/ CCM.0000000000001028.

14. Mouloudi E, Protonotariou E, Zagorianou A, losifidis E, Karapanagiotou A, Giasnetsova T, Tsioka A, Roilides E, Sofianou D, Gritsi-Gerogianni N. Bloodstream infections caused by metallo- $\beta$-lactamase/Klebsiella pneumonia carbapenemase-producing K. pneumoniae among intensive care unit patients in Greece: risk factors for infection and impact of type of resistance on outcomes. Infect Control Hosp Epidemiol. 2010;31:1250-6. https ://doi.org/10.1086/657135.

15. Pinheiro MR, Lacerda HR, Melo RG, Maciel MA. Pseudomonas aeruginosa infections: factors relating to mortality with emphasis on resistance pattern and antimicrobial treatment. Braz J Infect Dis. 2008;12:509-15. https //doi.org/10.1590/s1413-86702008000600013.

16. Blot S, Vandewoude K, De Bacquer D, Colardyn F. Nosocomial bacteremia caused by antibiotic-resistant gram-negative bacteria in critically ill patients: clinical outcome and length of hospitalization. Clin Infect Dis. 2002;34:1600-6. https://doi.org/10.1086/340616.

17. Ortega B, Groeneveld AB, Schultsz C. Endemic multidrug-resistant Pseudomonas aeruginosa in critically ill patients. Infect Control Hosp Epidemiol. 2004;25:825-31. https://doi.org/10.1086/502303.

18. Katsaragakis S, Markogiannakis H, Samara E, Pachylaki N, Theodoraki EM, Xanthaki A, Toutouza M, Toutouzas K, Theodorou D. Predictors of mortality of Acinetobacter baumannii infections: a 2-year prospective study in a Greek surgical intensive care unit. Am J Infect Control. 2010;38:631-5. https://doi.org/10.1016/j.ajic.2010.01.009.

19. Vardakas KZ, Rafailidis PI, Konstantelias AA, Falagas ME. Predictors of mortality in patients with infections due to multi-drug resistant Gram negative bacteria: the study, the patient, the bug or the drug? J Infect. 2013;66:401-14. https://doi.org/10.1016/j.jinf.2012.10.028.

20. Paramythiotou E, Routsi C. Association between infections caused by multidrug-resistant gram-negative bacteria and mortality in critically ill patients. World J Crit Care Med. 2016;5:111-20. https://doi.org/10.5492/ wjccm.v5.i2.111.

21. Turnbull AE, Rabiee A, Davis WE, Nasser MF, Venna VR, Lolitha R, Hopkins RO, Bienvenu OJ, Robinson KA, Needham DM. Outcome measurement in ICU survivorship research from 1970 to 2013: a scoping review of 425 publications. Crit Care Med. 2016:44(7):1267-77. https://doi.org/10.1097/ CCM.0000000000001651.

22. Kaarlola A, Tallgren M, Pettilä V. Long-term survival, quality of life, and quality-adjusted life-years among critically ill elderly patients. Crit Care Med. 2006;34:2120-6. https://doi.org/10.1097/01.CCM.0000227656.31911 .2E.

23. Vainiola T, Roine RP, Pettilä V, Kantola T, Rasanen P, Sintonen H. Effect of health-related quality-of-life instrument and quality-adjusted life year calculation method on the number of life years gained in the critical care setting. Value Health. 2011;14:1130-4. https://doi.org/10.1016/j. jval.2011.05.047.

24. Playford EG, Craig JC, Iredell JR. Carbapenem-resistant Acinetobacter baumannii in intensive care unit patients: risk factors for acquisition, infection and their consequences. J Hosp Infect. 2007;65:204-11. https:// doi.org/10.1016/j.jhin.2006.11.010.

25. Tansarli GS, Karageorgopoulos DE, Kapaskelis A, Falagas ME. Impact of antimicrobial multidrug resistance on inpatient care cost: an evaluation of the evidence. Expert Rev Anti Infect Ther. 2013;11:321-31. https://doi. org/10.1586/eri.13.4.

26. Cosgrove SE. The relationship between antimicrobial resistance and patient outcomes: mortality, length of hospital stay, and health care costs. Clin Infect Dis. 2006;42(Suppl 2):82-9. https://doi.org/10.1086/499406.

27. Marshall JC, Cook DJ, Christou NV, Bernard GR, Sprung CL, Sibbald WJ. Multiple organ dysfunction score: a reliable descriptor of a complex clinical outcome. Crit Care Med. 1995;23(10):1638-52. https://doi. org/10.1097/00003246-199510000-00007.

28. Horan TC, Andrus M, Dudeck MA. CDC/NHSN surveillance definition of health care-associated infection and criteria for specific types of infections in the acute care setting. Am J Infect Control. 2008;36(5):309-32. https://doi.org/10.1016/j.ajic.2008.03.002.

29. Kerridge RK, Glasziou PP, Hillman KM. The use of "Quality-Adjusted Life Years" (QALYs) to evaluate treatment in intensive care. Anaesth Intensive Care. 1995;23:322-31. https://doi.org/10.1177/0310057×9502300309.

30. Herdman M, Gudex C, Lloyd A, Janssen MF, Kind P, Parkin D, Bonsel G, Badia X. Development and preliminary testing of the new five-level version of EQ-5D (EQ-5D-5L). Qual Life Res. 2011;20:1727-36. https://doi. org/10.1007/s11136-011-9903-X.

31. Dolan P. Modeling valuations for EuroQol health states. Med Care 1997;35:1095-108. https://doi.org/10.1097/00005650-199711000-00002. 
32. Maragakis LL, Perencevich EN, Cosgrove SE. Clinical and economic burden of antimicrobial resistance. Expert Rev Anti Infect Ther. 2008;6:75163. https://doi.org/10.1586/14787210.6.5.751.

33. Prescott HC, Angus DC. Enhancing recovery from sepsis: a review. JAMA. 2018;319:62-75. https://doi.org/10.1001/jama.2017.17687.

34. Capuzzo M, Volta C, Tassinati T, Moreno R, Valentin A, Guidet B, lapichino G, Martin C, Perneger T, Combescure C, Poncet A, Rhodes A, Working Group on Health Economics of the European Society of Intensive Care Medicine. Hospital mortality of adults admitted to Intensive Care Units in hospitals with and without Intermediate Care Units: a multicentre European cohort study. Crit Care. 2014;18:551. https://doi.org/10.1186/ s13054-014-0551-8.

35. Holmes NE, Turnidge JD, MunckhofWJ, Robinson JO, Korman TM, O'Sullivan MV, Anderson T, Roberts SA, Gao W, Christiansen KJ, Coombs GW, Johnson PD, Howden BP. Antibiotic choice may not explain poorer outcomes in patients with Staphylococcus aureus bacteremia and high vancomycin minimum inhibitory concentrations. J Infect Dis. 2011;204:340-7. https://doi.org/10.1093/infdis/jir270.

36. Rello J, Rué M, Jupert P, Muses G, Soñora R, Vallés J, Niederman MS. Survival in patients with nosocomial pneumonia: impact of the severity of illness and the etiologic agent. Crit Care Med. 1997;25:1862-7. https:// doi.org/10.1097/00003246-199711000-00026.

37. Kang Cl, Kim SH, Park WB, Lee KD, Kim HB, Kim EC, Oh MD, Choe KW. Bloodstream infections caused by antibiotic-resistant gram-negative bacilli: risk factors for mortality and impact of inappropriate initial antimicrobial therapy on outcome. Antimicrob Agents Chemother. 2005:49:760-6. https://doi.org/10.1128/AAC.49.2.760-766.2005.

38. Kumar A, Ellis P, Arabi Y, Roberts D, Light B, Parrillo J, Dodek P, Wood G, Kumar A, Simon D, Peters C, Ahsan M, Chateau D, Cooperative Antimicrobial Therapy of Septic Shock Database Research Group. Initiation of inappropriate antimicrobial therapy results in a fivefold reduction of survival in human septic shock. Chest. 2009;136:1237-48. https://doi. org/10.1378/chest.09-0087.

39. Marchaim D, Gottesman T, Schwartz O, Korem M, Maor Y, Rahav G, Karplus R, Lazarovitch T, Braun E, Sprecher H, Lachish T, Wiener-Well Y, Alon D, Chowers M, Ciobotaro P, Bardenstein R, Paz A, Potasman I, Giladi M, Schechner V, Schwaber MJ, Klarfeld-Lidji S, Carmeli Y. National multicenter study of predictors and outcomes of bacteremia upon hospital admission caused by Enterobacteriaceae producing extended-spectrum beta-lactamases. Antimicrob Agents Chemother. 2010;54:5099-104. https ://doi.org/10.1128/AAC.00565-10.

40. Moreno R, Miranda DR, Matos R, Fevereiro T. Mortality after discharge from intensive care: the impact of organ system failure and nursing workload use at discharge. Intensive Care Med. 2001;27:999-1004. https ://doi.org/10.1007/s001340100966.

41. Goldfrad C, Rowan K. Consequences of discharges from intensive care at night. Lancet. 2000;355:1138-42. https://doi.org/10.1016/S0140 $-6736(00) 02062-6$.
42. Combes A, Costa MA, Trouillet JL, Baudot J, Mokhtari M, Gibert C, Chastre J. Morbidity, mortality, and quality-of-life outcomes of patients requiring $>$ or=14 days of mechanical ventilation. Crit Care Med. 2003;31(5):137381. https://doi.org/10.1097/01.CCM.0000065188.87029.C3.

43. Chelluri L, Im KA, Belle SH, Schulz R, Rotondi AJ, Donahoe MP, Sirio CA, Mendelsohn AB, Pinsky MR. Long-term mortality and quality of life after prolonged mechanical ventilation. Crit Care Med. 2004;32(1):61-9. https ://doi.org/10.1097/01.CCM.0000098029.65347.F9.

44. Exner M, Bhattacharya S, Christiansen B, Gebel J, Goroncy-Bermes P, Hartemann P, Heeg P, Ilschner C, Kramer A, Larson E, Merkens W, Mielke M, Oltmanns P, Ross B, Rotter M, Schmithausen RM, Sonntag HG, Trautmann M. Antibiotic resistance: what is so special about multidrug-resistant Gram-negative bacteria? GMS Hyg Infect Control. 2017;12:05. https://doi. org/10.3205/dgkh000290.

45. Wang T, Derhovanessian A, De Cruz S, Belperio JA, Deng JC, Hoo GS. Subsequent infections in survivors of sepsis: epidemiology and outcomes. J Intensive Care Med. 2014;29:87-95. https://doi.org/10.1177/0885066612 467162.

46. Angus DC, Musthafa AA, Clermont G, Griffin MF, Linde-Zwirble WT, Dremsizov TT, Pinsky MR. Quality-adjusted survival in the first year after the acute respiratory distress syndrome. Am J Respir Crit Care Med. 2001;163(6):1389-94. https://doi.org/10.1164/ajrccm.163.6.2005123.

47. Añón JM, García de Lorenzo A, Zarazaga A, Gomez-Tello V, Garrido G. Mechanical ventilation of patients on long-term oxygen therapy with acute exacerbations of chronic obstructive pulmonary disease: prognosis and cost-utility analysis. Intensive Care Med. 1999;25(5):452-7. https://doi. org/10.1007/s001340050879.

48. Graf J, Mühlhoff C, Doig GS, Reinartz S, Bode K, Dujardin R, Koch KC,

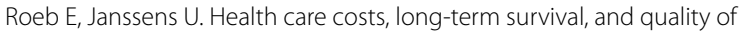
life following intensive care unit admission after cardiac arrest. Crit Care. 2008;12(4):R92. https://doi.org/10.1186/cc6963.

49. Lone NI, Walsh TS. Impact of intensive care unit organ failures on mortality during the five years after a critical illness. Am J Respir Crit Care Med. 2012;186(7):640-7. https://doi.org/10.1164/rccm.201201-00590C.

50. Sam JE, Lim CL, Sharda P, Wahab NA. The organisms and factors affecting outcomes of external ventricular drainage catheter-related ventriculitis: a penang experience. Asian J Neurosurg. 2018;13(2):250-7. https://doi. org/10.4103/ajns.AJNS_150_16.

\section{Publisher's Note}

Springer Nature remains neutral with regard to jurisdictional claims in published maps and institutional affiliations.
Ready to submit your research? Choose BMC and benefit from:

- fast, convenient online submission

- thorough peer review by experienced researchers in your field

- rapid publication on acceptance

- support for research data, including large and complex data types

- gold Open Access which fosters wider collaboration and increased citations

- maximum visibility for your research: over 100M website views per year

At BMC, research is always in progress.

Learn more biomedcentral.com/submissions 